\title{
ОСОБЕННОСТИ ФОРМИРОВАНИЯ ЛЕДНИКОВОГО РЕЛЬЕФА КАРУЛАСКОЙ ВОЗВЫШЕННОСТИ
}

Карулаский ледниковый комплекс в Южной Эстонии относится к числу возвышенностей Восточно-Балтийского ледораздела, расположенного между Балтийским и Чудским ледниковыми потоками. На основании существующих представлений о гляциодинамике последнего ледникового покрова на территории Юго-Восточной Эстонии и Северо-Восточной Латвии и новых данных о морфологии ледникового рельефа можно заключить, что в пределах возвышенности преобладают формы рельефа мертвого льда и лишь изредка встречаются образования, свидетельствующие в пользу активности ледниковых выступов, как например, в контактной зоне разнонаправленных Выртсъярвского и Выру-Харглаского (Средне-Гауйского) языков.

Площадь Карулаской возвышенности составляет около 300 км² (Karukäpp, 1972). Наибольшие абсолютные отметки достигают здесь 137 м (Ребазеярве Торнимяги), относительная высота возвышенности составляет лишь 30-40 , высота повышения коренного рельефа среднедевонских песчаников в пределах возвышенности - $30 \mu$. Несмотря на скромные в среднем высоты, рельеф Карулаской возвышенности резко выступает над волнистой Выру-Харглаской долиной и друмлинизированной Выртсъярвской впадиной.

Комплекс Каруласких ледниковых образований морфологически и генетически тесно связан с Отепяской возвышенностью (Granö, 1922; Tammekann, 1933; Каяк, 1963). Его рельеф обычно описывается как холмисто-моренный (Орвику, 1955; Orviku, 1960; и др.) К. Ф. Каяк* характеризует Каруласкую возвышенность как сложный комплекс краевых ледниковых образований, состоящих в проксимальной части из конечно-моренной полосы, в средней - из озовых гряд с отдельными камамн и в дистальной части из вогнутого зандрового поля. Позднее, обобщая материалы среднемасштабной геологической съемки, К. Ф. Каяк (1963) выделяет в пределах Карулаского ледникового комплекса среднеи мелкохолмистый моренный и камовый рельеф (местами с напорными образованиями), а также средне- и мелкохолмистый камовый (флювиогляциальный) рельеф.

В результате морфометрического анализа гипсометрических схем и анализа почвенных карт нами (Karukäpp, 1974) в пределах Карулаской возвышенности выделено четыре типа рельефа и в их пределах три подтипа (рис. 1). При этом принимали во внимание холмистость (число положительных форм на $1 \kappa м^{2}$ ), расчлененность и

* Ka ja k K. Valga, Antsla ja Mõniste ümbruse kvaternaargeoloogiast. ная работа в фондах кафедры геологнн ТГУ. Тарту, 1953.

Диплом- 
процентуальное содержание типичных по высоте форм рельефа. Расчлененность вычислялась по суммарной длине горизонталей на $1 \kappa \mu^{2}$ и по данным интенсивности почвенной эрозии. Расхождение результатов этих двух методов не превышало $0,5^{\circ}$ на средних уклонах поверхности. С целью отражения предыдущей активности ледника, используется классификация рельефа С. П. Гравенора и В. О. Купша (Gravenor, Kupsch, 1959).

Согласно геоморфологической схеме (рис. 1) Карулаской возвышенности и территорий соседних гляциодепрессий, формы рельефа в зависи-

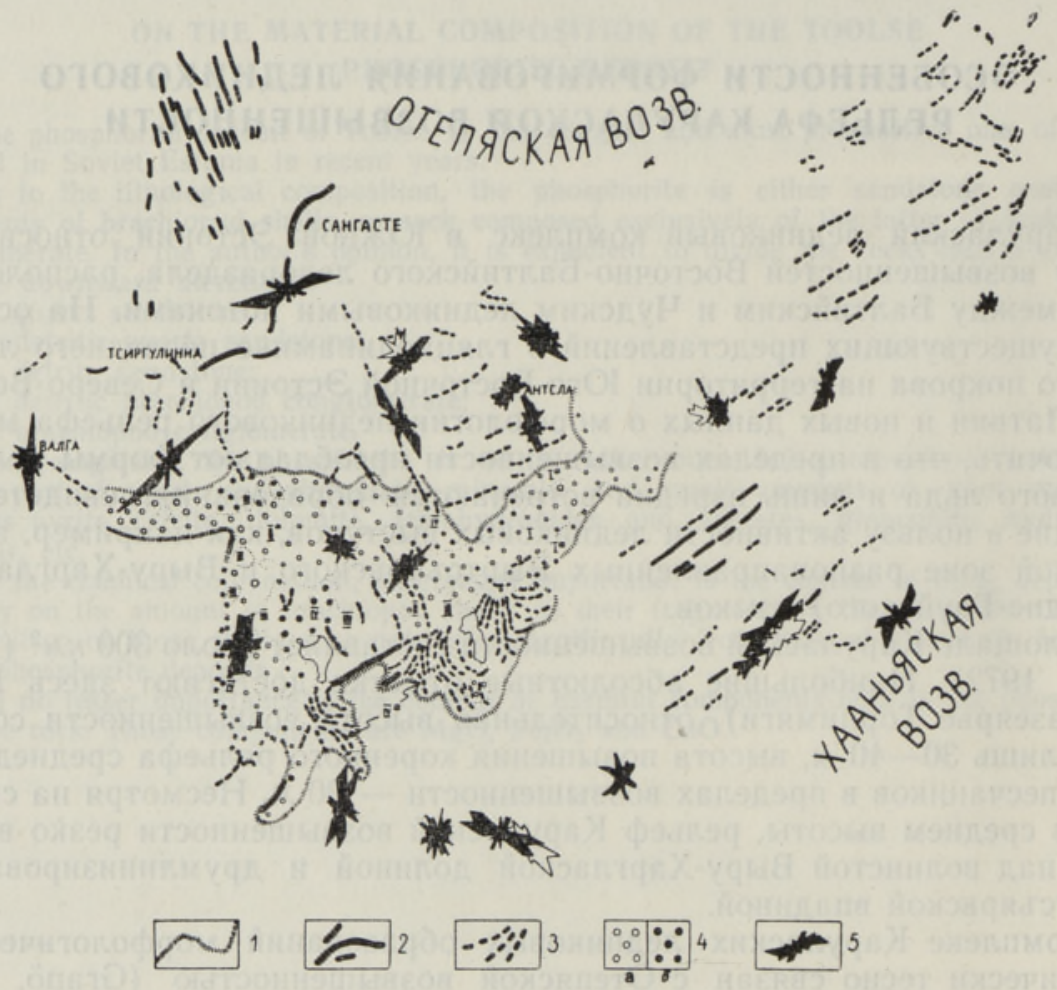

Рис. 1. Геоморфологическая схема Карулаской возвышенности: 1 - граница возвышенности; 2 - формы активного ледника (друмлины, конечные морены) ; 3 - унаследованно-ориентированный рельеф мертвого льда; 4 - беспорядочно расположенный холмистый рельеф мертвого льда: $a$ - холмы и гряды с моренной покрышкой, 6 - камы; 5 - ориентировка галек в морене.

мости от гляциодинамических особенностей генезиса можно условно подразделить на формы активного (друмлины, конечные морены) и формы мертвого льда (распада ледника); последние, в свою очередь, делятся на унаследованно-ориентированные и беспорядочно расположенные. Унаследованно-ориентированные формы рельефа отражают систему трещин в мертвом льду, которые возникли вслед за динамическими трещинами, закономерно ориентированными относительно направления движения льда (Embleton, King, 1968; Асеев, 1969).

Формы холмистого рельефа Карулаской возвышенности имеют обычно моренную покрышку на водно-ледниковых отложениях. Для района куполовидных холмов (рис. 1, I и I ${ }^{\mathrm{a}}$ ) свойственна высокая степень холмистости (25 положительных форм на $\left.1 \kappa \mu^{2}\right)$, причем преобладают холмы высотой $10-25$ м, и наибольшая для Қарулаской возвышенности 
расчлененность рельефа (средний уклон земной поверхности превышает $\left.6^{\circ}\right)$.

Район холмов и гряд с моренной покрышкой (рис. 1, II и II ${ }^{a}$ ) характеризуется сложными формами рельефа неправильного очертания и рассеянным расположением крупных (высотой более 25 м) холмов и гряд среди средних и мелких форм. Число положительных форм не превышает 17 на $\kappa \mu^{2}$. Средний уклон земной поверхности колеблется в пределах 3-5․ Расчлененность ледникового рельефа несколько понижена в результате торфонакопления (заболоченность холмистого рельефа доходит до $25 \%$ ).

Моренная покрышка на водно-ледниковых отложениях обычно не превышает $2-3$ м. Морена часто наблюдается и в ядрах форм рельефа и в виде линз в водно-ледниковых отложениях, но количественно, в составе отложений холмистого рельефа, несомненно, водно-ледниковые отложения преобладают над мореной. При характеристике рельефа возвышенностей Юго-Восточной Эстонии К. Ф. Каяк (1963) определяет подобные формы рельефа как флювиогляциальные и лимногляциальные камы с чехлом из абляционной морены. При описании Северо-Эстонских краевых образований употребляется понятие «внутриледниковые камы с моренной покрышкой» (Раукас и др., 1971). Учитывая то, что моренная покрышка играет важную роль в формировании почвенного покрова и ландшафтов, такие формы рельефа называть камами, видимо, нецелесообразно. Применяемый некоторыми исследователями термин «морена мертвого льда» (Niewiarovski, 1965; Басаликас, 1969) также не вполне удачен, так как под мореной в русском языке подразумевают преимущественно отложения, а не формы рельефа. Поэтому невольно приходится принять неудобно длинное определение - «холмы с моренной покрышкой».

Озо-камовый рельеф Карулаской возвышенности (рис. 1, IVа; рис. 2) состоит из коротких $\left(50-300\right.$ м) крутосклонных (до $24^{\circ}$ ) озоподобных ориентированных гряд, высота которых обычно не превышает $10 \mu$. Озокамы имеют острые гребни и узкие $V$-образные поперечные профили межгрядовых понижений. Количество положительных форм на $1 \kappa \mu^{2}$ достигает местами 50, т. е. вдвое больше, чем в районе распространения холмистого рельефа. Расчлененность рельефа понижена в результатє обширного заболачивания территории $(30-40 \%)$.

Особенности формирования Чудского и Выртсъярвского ледниковых потоков, а также подстилающий рельеф Отепяской островной возвышенности предопределили условия формирования Карулаской зоны осадконакопления. Направление Выртсъярвского потока отражается на ориентировке друмлинов и радиальных систем холмистых гряд севернее и северо-западнее Карулаской возвышенности (рис. 1). Юго-западное направление движения ледника вдоль Выру-Харглаской долины установлено по ориентировке удлиненных, в том числе друмлиноподобных, форм рельефа, а также по ориентировке галек в морене Выру-Харглаской долины и Средне-Гауйской низменности (Аболтынь и др., 1972). Такое же направление предполагалось и в результате анализа ориентировки контуров почвенных разновидностей (Raukas, 1961).

Сравнительный геоморфологический анализ позволяет считать формирование Карулаского ледникового комплекса более поздним и кратковременным, чем Отепяской островной возвышенности (первый расположен гипсометрически ниже и имеет только единичные крупные сложные формы рельефа). Отсутствие платообразных лимнокамов, которые характерны для центральной части Отепяской возвышенности, и преобладание мелко- и среднехолмистого рельефа свидетельствуют о том, что 
во время формирования рельефа Карулаской возвышенности ледник был сравнительно маломощным.

Для объяснения генезиса рельефа рассматриваемой возвышенности мы предполагаем существование в леднике придонных течений, направление которых существенно отличалось от общего направления движения ледника. Автономные направления движения придонных слоев льда в малых масштабах отражаются в ориентировке ледниковой штриховки (Demorest, 1938, с. 707). Разнонаправленность в вертикальном сечении ледника предполагается и при объяснении аномалий распространения эрратических валунов (Embleton, King, 1968, с. 305). Направление движения придонного льда ледника тесным образом связано с характером подстилающего рельефа.

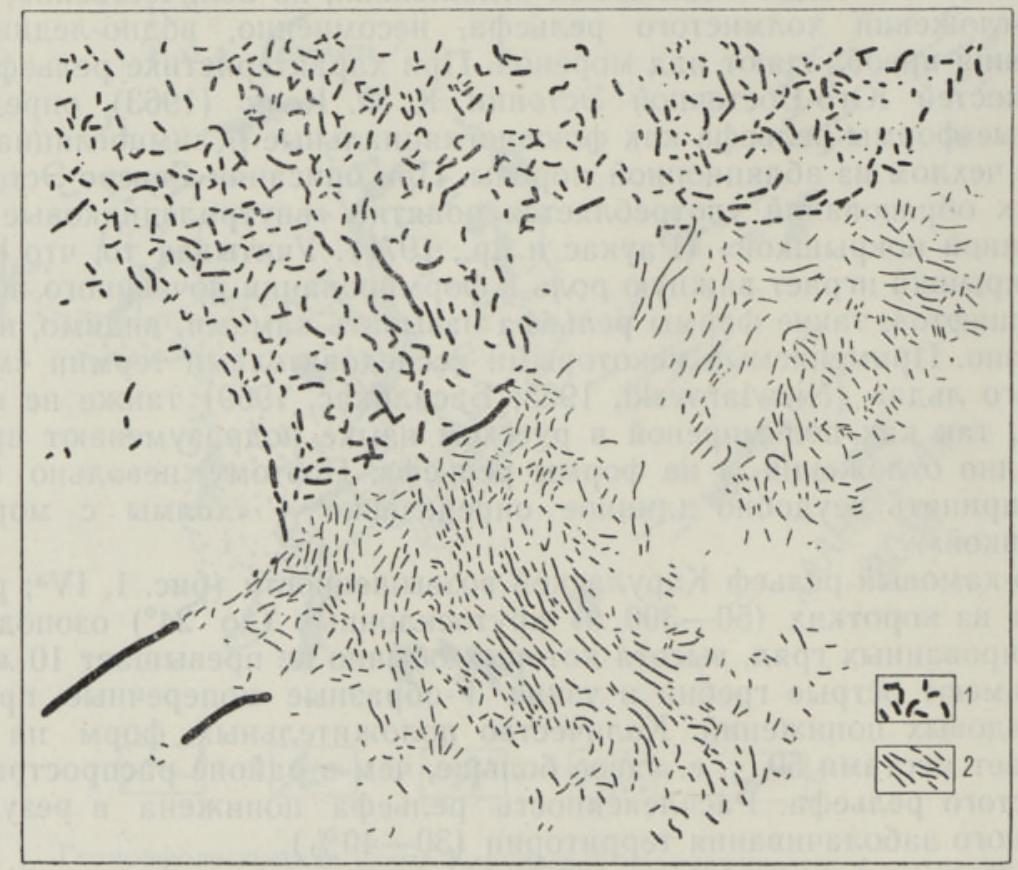

Рис. 2. Расположение осей удлиненных форм рельефа в южной части Карулаской возвышенности: 1 - холмистый рельеф (преимущественно с моренной покрышкой); 2 - озо-камовый рельеф.

До возникновения Карулаского ледникового комплекса сравнительно мощный Выртсъярвский поток, обтекавший покрытую мертвым льдом центральную часть Отепяской возвышенности, покрыл ответвление Чудского потока в Выру-Харглаской долине (рис. $3, A)$. Последнее, в свою очередь, стало препятствием для нижних слоев Выртсъярвского потока, обусловливая их отмирание, а возможно, и сохранение отложений предыдущего оледенения.

В процессе последующего уменьшения общей мощности льда краевая часть ледника распадалась на разнонаправленные лопасти и языки (рис. $3, Б)$. Первым этапом формирования рельефа Карулаской возвышенности можно считать период концентрации моренного материала в краевой части Выртсъярвского языка. Әтот этап начался, вероятно, в донных слоях за препятствием Выру-Харглаского придонного течения еще до расчленения ледника на языки. 
Высокое содержание моренного материала в леднике служило дополнительной предпосылкой для формирования мертвого льда между ВыруХаргласким (Средне-Гауйским) и Выртсъярвским ледниковыми языками.

Северная граница Карулаского холмистого рельефа явно не служила зоной расчленения между активным и мертвым льдом, т. к. здесь отсутствуют конечные морены и маргинально расположенные холмистые гряды. Зоны расчленения ледникового льда с разным динамическим состоянием существовали в начале формирования Карулаского комплекса между краем Выртсъярвского языка и Выру-Харгласким языком (Кообассаареская конечная морена) и в завершающий этап между активным и мертвым льдом в Выртсъярвской языковой депрессии, примерно в 10 км северо-западнее от склона Карулаской возвышенности (конечная морена между Сангасте и Тсиргулинна).
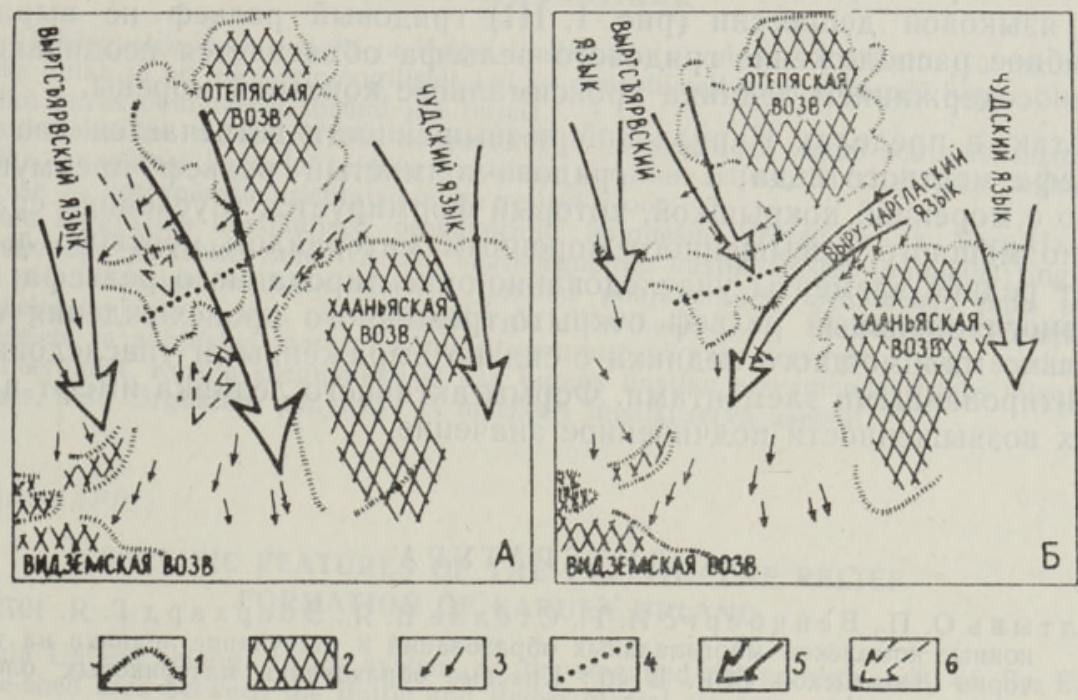

Рис. 3. Динамика ледникового покрова в разные стадии формирования Карулаской возвышенности: 1 - границы возвышенности; 2 - мертвый лед; 3 - ориентировка галек в морене; 4 - зона контакта Выртсъярвского и Выру-Харглаского ледниковых языков; 5 - направление движения лед. ника; 6 - направление прндонных слоев льда.

После насыщения краевой части Выртсъярвского языка моренным материалом и уменьшения мощности льда отмирание ледника не ограничилось узкой краевой чайью мореносодержащего льда, а охватило полосу шириной 20-30 км до конечной морены между Сангасте и Тсиргулинна. Соответственно этому Карулаские ледниковые образования нельзя считать краевыми образованиями в строгом понимании этого слова (Даниланс, 1963; Раукас и др., 1971; и др.).

Пологие маргинальные валы высотой 5-10 $\mu$ в центральной части языковой депрессии образовались, по всей вероятности, подо льдом Выртсъярвского языка и, следовательно, не могут маркировать положение края ледника. Я. Лундквист объясняет формирование подобных форм выдавливанием моренного материала в придонные трещины растяжения (Lundqvist, 1969).

Движение льда Средне-Гауйского языка имело в Выру-Харглаской долине транзитный характер, т. е. маргинальные препятствия, вызывав-

5 ENSV TA Toimetised $\mathrm{K} \cdot \mathrm{G}-21975$ 
шие концентрацию моренного материала в леднике, здесь отсутствовали. В суженной части долины происходило формирование друмлинизированного рельефа, например, в нижнем течении р. Пярлийыги. В расширенной же части, в стороне от осевой линии течения, образовались поля малоподвижного льда со сложной системой трещин, отражением которых является озо-камовый унаследованно-ориентированный рельеф в юго-восточной части возвышенности. Расположение отдельных гряд озо-камов (рис. 2) напоминает густую сеть системы, несколько смещенную относительно места возникновения маргинальных трещин, которые образовались в боковой части долинного ледника (Embleton, King, 1968). После отмирания ледникового языка трещины углублялись талыми водами и заполнялись водно-ледниковыми отложениями из мертвого льда краевой части соседнего Выртсъярвского языка.

Проксимальнее Кообассаареской конечной морены распространяется холмистый рельеф, дистальнее - озо-камовый. Лишь дистальнее небольшой языковой депрессии (рис. 1, III) грядовый рельеф не выражен. Подобное расположение грядового рельефа объясняется неодинаковым мореносодержанием ледника проксимальнее конечной морены.

Итак, в пределах Карулаской возвышенности встречается два типа рельефа мертвого льда: 1 - грядово-холмистый рельеф преимущественно с моренной покрышкой, который формируется в условиях сравнительно мощного, насыщенного моренным материалом мертвого льда и имеет редкие элементы унаследованно-ориентированного рельефа; 2 флювиогляциальный рельеф открыто-трещинного происхождения сравнительно маломощного ледника с сильно выраженными унаследованноориентированными элементами. Формы активного ледника имеют в пределах возвышенности подчиненное значение.

\section{ЛИТЕРАТУРА}

А болтынь О. П., Вейнбергс И. Г., Стелле В. Я., ЭберхардГ. Я. 1972. Основные комплексы маргинальных образований и отступание ледника на территории Латвийской ССР. В сб.: Краевые образования материковых оледенений. $M$.

А се е в А. А. 1969. Рельефообразующая роль мертвого льда при деградации древних европейских материковых оледенений. В сб.: Землеведение, 8 (48). М.

Б а с а ли к а с А. В. 1969. Разнообразие рельефа ледниково-аккумулятивной области. В сб.: Материковое оледенение и ледниковый морфогенез. Вильнюс.

Д а н и л а н с И. Я. 1963. К истории выделения маргинальных форм на территории Латвин. Тр. Комис. по изучению четвертичного периода, XXI. М.

К ая к К. Ф. 1963. О краевых ледниковых образованиях Юго-Восточной Эстонии. Тр. Комис. по изучению четвертичного периода, XXI. М.

О р в и ку К. К. 1955. Основные черты геологического развития территории Эстонской ССР в антропогеновом периоде. Изв. АН ЭССР, IV, № 2.

Р а ука с А., Р яхни Э., Мнйдел А. 1971. Краевые ледниковые образования Северной Эстонин. Таллин.

Demorest $M$. 1938. Ice flowage as revealed by glacial striage, Journ. Geol., 46, $700-725$.

Emblet on C., King C. A. M. 1968. Glacial and periglacial geomorphology. Edinburgh.

Gr a n ö J. G. 1922. Eesti maastikulised üksused. Loodus, nr. 2, 105-123.

Gravenor C. P., Kupsch W. O. 1959. Ice-disintegration features in western Canada. Journ. Geol., 67, 48-64.

K a r u käpp R. 1974. Karula kõrgustiku reljeefist. EGS-i aastaraamat 1973. Tallinn.

L u n d q v is t J. 1969. Problems of so-called rogen moraine. Sver. Geol. undersökn., C., Nr. 648,32 .

Niewiarowski W. 1965. Kemi i formi pokrowne w Danii oraz rozmieszczenie obszarow kemowych na terenie Peribalticum w obrebie ostatniego zlodowacenia. Zeszyty naukowe Univ. M. Kopernika w Toruniu, nauki matem.-przyrod., zesz.11, geogr. IV. 116 st. 
Orviku K. 1960. Eesti geoloogilisest arengust antropogeenis I. Eesti Loodus, nr. 1, Rauk as A. S A. 1961. Mandrijää liikumisest Eestis. Eesti Loodus, nr. 5, 259-264. T a m me ka n n A. 1933. Eesti maastikutüübid. Publicationes Instituti Universitatis
Tartuensis Geographici. Tartu, $3-21$.

Ннститут геологии

Академии наук Эстонской ССР

Поступила в редакцию

31/VII 1974

Reet KARUKAPP

\section{LIUSTIKULISE RELJEEFI KUJUNEMISE ISEARASUSED KARULA KORGUSTIKUL}

Karula kõrgustik kuulub Balti ja Peipsi liustikuvoolu vahelise Ida-Balti jäälahkmeala kõrgustike hulka ja on nii morfoloogiliselt kui ka geneetiliselt seotud Otepää kõrgustikuga.
Kõrgustiku piires domineerib surnud jää reljeef.

Liustikutekkeline reljeef Karula kōrgustikul ja naaberaladel jaotub sōltuvalt liustikudünaamika omapärast kolmeks tüübiks: aktiivse liustiku reljeef, surnud jäăs tekkinud

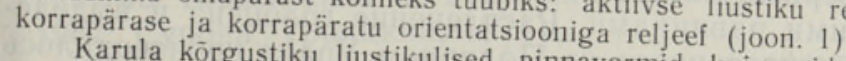
erineva suunaga jääkeelte vahel. Otepääavormid kujunesid Võrtsjärve ja Võru-Hargla erinevad jää liikumissuunad eksisteerisid liustikustiku liustikualusest tuumikust tingitud liustikukeelte tekkimist (joon. 3). Vōru-Harstiku põhjakihtides tōenäoliselt juba enne liustikukeelele ja põhjustas moreeni kontsentreen liustikukeel oli takistuseks Võrtsjärve jää stagneerumist. Karula kõrgustikkuntsentreerumist viimase servaalal ning soodustas tähenduses, sest kõrgustiku pōhjanōlvu ei saa lugeda liustiku servamoodustisteks kitsamas

\section{Reet KARUKÄPP}

\section{SPECIFIC FEATURES OF THE PLEISTOCENE RELIEF FORMATION OF KARULA UPLAND}

Karula Upland belongs to the system of the so-called island-highlands of the East Baltic ice-shed area between the Baltic and Peipsi glacial streams, and is morphologically
and genetically connected with Otepäal dead ice relief predominates.

The glacial relief of the Upland and neighbouring territory can be divided into three
types, depending on the dynamics of the glacier ice: the relief of active ice; controlled features of disintegration of dead ice, represented by: the relief of active ice; controlled features of disintegration of dead ice, represented by an orientated relief; uncontrolled

The glacial relief of Karula Upland is formed by an irregular relief (Fig. 1). glacial lobes, which had different directions. These different directionarv and Vôru-Hargla the bottom strata of the glacier, which were produced by Otepää Uplans of ice moving in been existing before the Võrtsjärv and Võru-Hargla glacier Otepää Upland, had probably

The stagnation of the Vörtsjärv glacier lobe was caused lobes were formed (Fig. 3). but we cannot consider Karula Upland to be a marginal formation the Vorru-Hargla lobe, as the northern slope of the upland does not mark the formation in its narrower sense, 